\title{
Fundamental Studies of the Effects of Photo-additive Structure on Resist Outgassing
}

\author{
F. M. Houlihan, I. L. Rushkin, R. S. Hutton, \\ A. G. Timko, E. Reichmanis, O. Nalamasu \\ Bell Laboratories, Lucent Technologies \\ 600 Mountain Avenue \\ Murray Hill, NJ \\ A. H. Gabor, A. N. Medina, S. Malik, M. Neiser \\ Arch Chemicals. \\ 200 Massasoit Avenue, East Providence, RI 02914 \\ R.R. Kunz, D. K. Downs \\ Lincoln Laboratory, Massachusetts Institute of Technology \\ 244 Wood St, Lexington Massachusetts, 02420-9108
}

\begin{abstract}
The effect of different photoadditives in high and low activation energy resist resins on resist outgassing during lithographic exposure was studied by quartz microbalance and gas chromatography/mass spectroscopy techniques. The resist outgassing was analyzed both qualitatively and quantitatively and structureproperty relationships were developed between resist outgassing and the molecular structure of photoacid generators (PAG) and other additives. The photoadditives examined included, aryl iodonium perfluoroalkylsulfonates, triarylsulfonium perfluoroakylsulfonates, photogenerators of sulfamic acids, 2-nitrobenzyl PAG's and doxyl derivatives. It was found that during exposure sulfonium salt formulated resists gave a lower outgassing of aromatic compounds than iodonium salt formulated resists while a formulation with a nitrobenzyl PAG did not show any aromatic materials outgassing. The use of a stable free radical additive, methyl 5doxyl stearate, in a resist formulated with an iodonium salt was found to also dramatically reduce outgassing of aromatic compounds probably through termination of triplet state radical photoproducts. Sweet PAG resist formulations were found to have greatly decreased outgassing during exposure originating from the cleavage of low activation energy acetal protecting groups.
\end{abstract}

Keywords: resist outgassing, photoacid generators, $193 \mathrm{~nm}, 248 \mathrm{~nm}$, e-beam.

\section{Introduction}

MIT Lincoln Laboratory has shown in their study of deep-UV and $193 \mathrm{~nm}$ photoresists that photo-products may outgas and condense on the exposure tool lens degrading its transmission and uniformity[1]. Similarly, degradation of e beam tool performance may occur if outgassing of photoresists during exposure degrades the high vacuum needed for this exposure mode. Consequently, resist outgassing during exposure is a problem which is of importance both in UV lithography $(248 \mathrm{~nm}, 193 \mathrm{~nm}, 157 \mathrm{~nm}$ and 
Extreme Ultraviolet) and vacuum lithographies (ebeam). Two preferred solutions to address the outgassing problem during UV exposure involve changing the geometry and purging design of the tool or changing the chemistry of the photoacid generator (PAG) in order to reduce the impact of the outgassing products. The latter approach is the subject of this paper. To probe the differing impact of various outgassing products, MIT Lincoln Laboratory has recently reported a study[1] employing quartz microbalance (QCM) and gas chromatography/mass spectroscopy (GCMS) to monitor outgassing. In this study, it was found that low activation energy chemically amplified (CA) resists tend to give a larger amount of outgassing than ones employing high activation energy protecting groups [1]. The outgassing rates generally ranged from $10^{10}$ to $10^{13}$ molecules $/ \mathrm{cm}^{2}-\mathrm{sec}$ or higher. Specifically, this work showed that the two most potent sources for outgassing, in order of importance, were cleavage of the dissolution inhibiting moiety (e.g. 2methyl-1-propene, aldehydes etc.) and photolysis of the photoacid generator (PAG), (e.g. in onium type PAG's; benzene, alkyl or halobenzene etc). Reducing the impact of outgassing is related to not only decreasing the total amount of outgassing but also in paying special attention to suppression of outgassing materials which are known to be especially deleterious with respect to deposition on exposure tool lens materials. Furthermore, it was found that for exposures at $193 \mathrm{~nm}$, aromatic outgassing products are much more readily deposited on lens materials than aliphatic ones [1]. This was discovered by examining the reduction in transmission of typical lens materials at $193 \mathrm{~nm}$ after exposure to various organic vapors during irradiation. Specifically, it was found that aromatic outgassing products, and expecially iodobenzene, (derived from photolysis of diphenyliodonium based photoacid generators (PAG's) (Scheme 1) were found to be especially deleterious[1]. Consequently, we have studied a variety of different chemical designs for PAG's and other additives aimed at reducing both total outgassing of resists during exposure and specific reduction of outgassing moieties such as haloaryls.

FIG. 1 shows the structure of the different photoadditives used in this study including bis(tbutylphenyl)iodonium nonaflate (1), tris(tbutylphenyl)sulfonium nonaflate (2), tris(tbutylphenyl)sulfonium nonaflate (3) bis(2.6dinitrobenzylethoxycarbonyl)benzyl 1,3benzenesulfonate (4), bis(t-butylphenyl)iodonium cyclamate "sweet PAG" (5), methyl 5doxystearate (6).
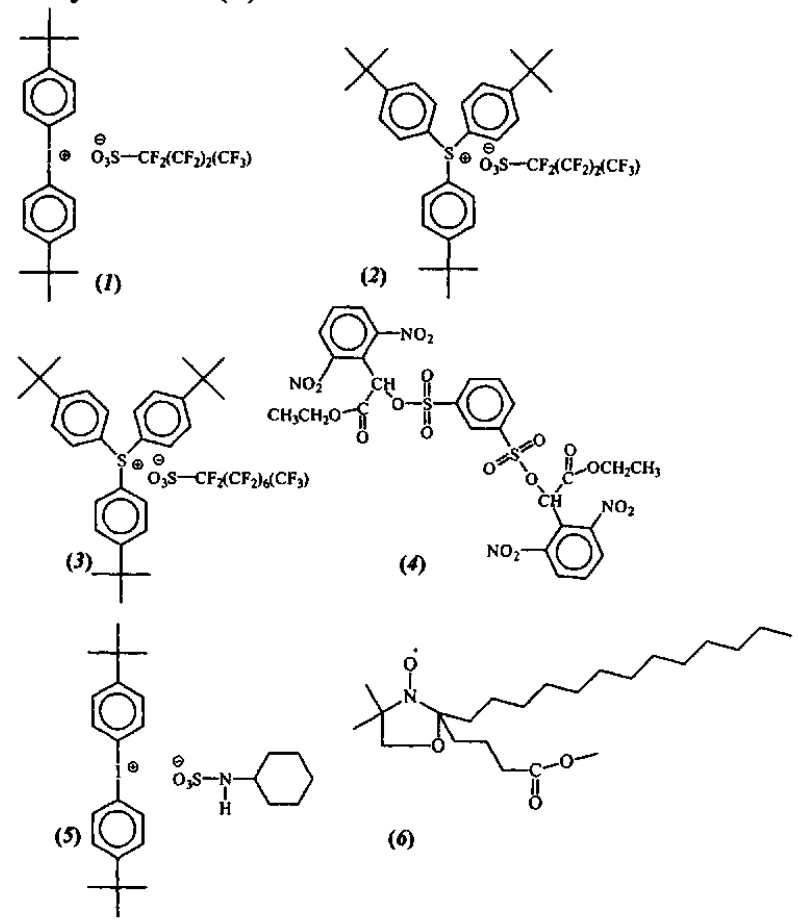

(6)

FIG. 1. Structure of photoadditives studied

\section{RESULTS AND DISCUSSION}

Two different polymer matrices were employed to study outgassing of volatiles as a function of changing the chemistry of photoadditives, namely resins containing either low or high activation energy groups.

\subsection{Scope of Experiments Done with Resins Protected with High Activation Energy Groups}

The high activation energy resist consisted of a $193 \mathrm{~nm}$ resist [2] bassed on a poly(norbornenealt-maleic anhydride-co-t-butylacrylate-co-acrylic) acid [P(NB/MA/TBA/AA)] polymer matrix protected with a t-butyl group formulated with a blend of dissolution inhibitors (DI's) [3] (FIG. 2). The studies in this resist matrix, done by exposure to $193 \mathrm{~nm}$ radiation, were aimed at better understanding the structure property relationships between resist outgassing and chromophores.

The chromophores studied were bis(tbutylphenyl)iodonium (1) tris(tbutylphenyl)sulfonium ( 2 and 3 ) and 2,6-dinitro$\alpha$-ethoxycarbonyllbenzyl (4). The tris(tbutylphenyl)sulfonium chromophore was of interest because it would impart good solubility to PAG's in solvents useful for formulation, are expected to give PAG's with low toxicity[4] and produce aryl photoproducts of lower volatility (Scheme 1). The 2,6-dinitro- $\alpha$-ethoxycarboxylbenzyl chromophore was chosen because it 
allowed the 2-nitrobenzyl ester sulfonate moiety to have adequate thermal stability to withstand the bakes employed during lithographic processing.

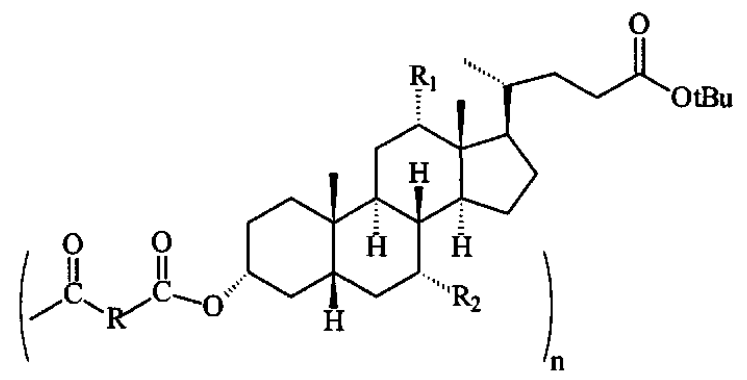<smiles>CCCCC(=O)OCCC(C)[C@H]1CCC2C3CC[C@H]4CC(O)CCC4(C)[C@H]3CC(O)C21C</smiles><smiles>CC1C2CCC(C2)C1C1C(=O)OC(=O)C1I</smiles>

P(NB/MA/TBA/AA

FIG 2. Resin components of high activation energy $193 \mathrm{~nm}$ resist

Indeed, the PAG employed in this latter study, PAG 4, was initially designed as a low diffusion, high temperature resistant materials for use in CAMP-6 $248 \mathrm{~nm}$ resists based on poly(tbutoxycarbonyloxystyrene-co-sulfone) derivatives [5].

Finally, a radical scavenging additive, methyl 5-doxystearate (6) (FIG. 1) was employed in an attempt to trap radicals formed by the triplet photochemical reaction pathway (Scheme 1) [6] during the irradiation of bis(tbutylphenyl)iodonium nonaflate. This would avoid the formation of undesirable volatile aromatic photoproducts such as t-butyliodobenzene forming instead non volatile photoproducts (Scheme 2, Table 1).

Stable radicals such as 6 are available through judicious substitution designed to enhance thermal stability[7]. For our application we specifically chose, an ester substituted material, 6 , to optimize both solubility in the resist matrix and to eschew complications which might arise from the use of functionalities which could affect resist dissolution (e.g. free carboxylic acid moiety).

\section{Scheme 1}<smiles>[R][Fe]=[R]([R])[R]</smiles><smiles>CC1CC1[13CH3]</smiles>

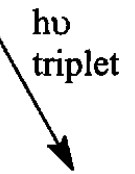

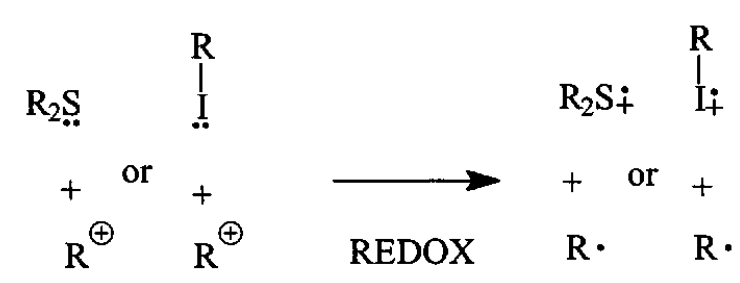

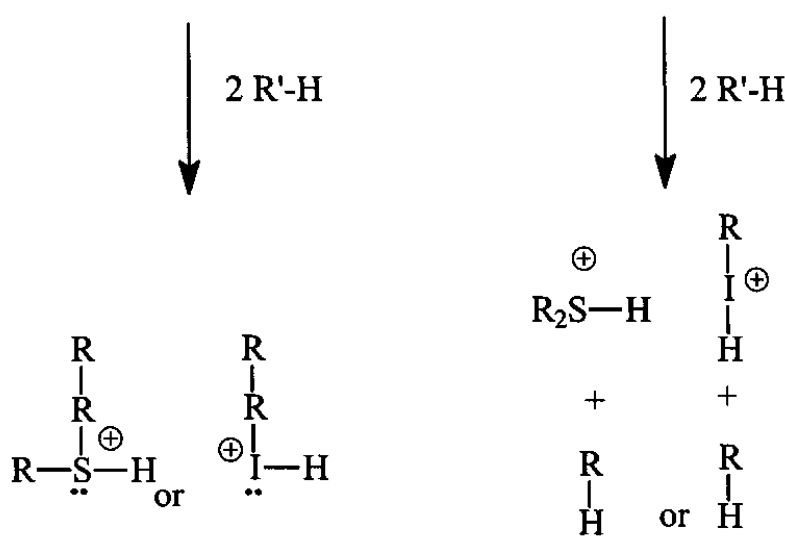

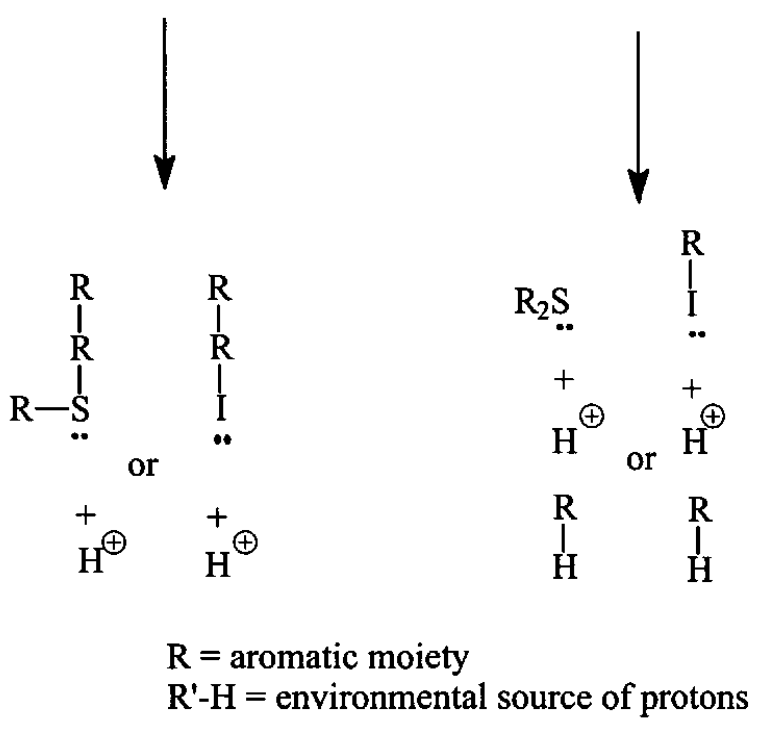

Indeed a key consideration in choosing all the structures of photoadditives we studied in the 
$\mathrm{P}(\mathrm{NB} / \mathrm{MA} / \mathrm{TBA} / \mathrm{AA})$ resist matrix was to consider the volatility of the aromatic photo-products which would result from their addition to the resist film.

\section{Scheme 2}

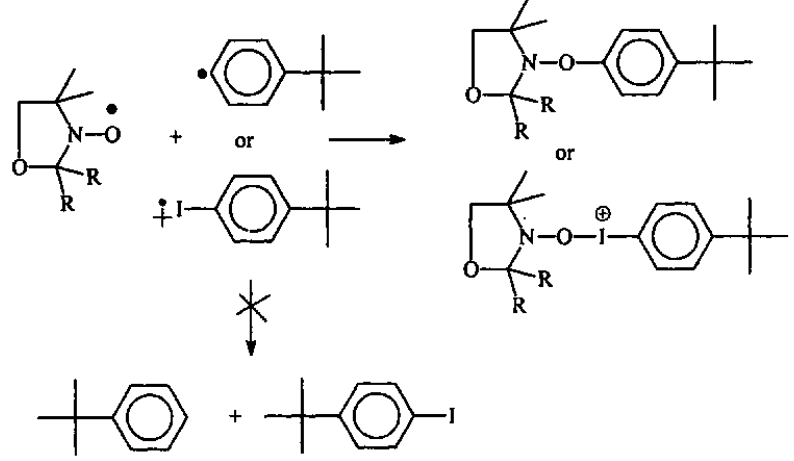

Table 1 shows a comparison of $\mathrm{Mw}$ and boiling points of photoproducts expected from these additives while FIG. 3 shows the vapor pressure of a sampling of various photoproducts. The significance of this data in light of the results of the outgassing experiments done in $\mathrm{P}(\mathrm{NB} / \mathrm{MA} / \mathrm{TBA} / \mathrm{AA})$ resist matrices will be discussed shortly.

\subsection{Results of Experiments Done with Resins Protected with High Activation Energy Groups \\ Table 2 gives a summary of the total outgassing measured by GCMS given off by the $\mathrm{P}(\mathrm{NB} / \mathrm{MA} / \mathrm{TBA} / \mathrm{AA})$ resist formulations upon exposure to $193 \mathrm{~nm}$.}

\subsubsection{Effect of PAG Chromophore}

The formulation containing the dinitrobenzylderivatived, PAG 4, exhibited a lower isobutene outgassing than that with the sulfonium nonaflate, PAG 2 or the iodonium nonaflate, PAG 1 (Table 3 and 4). This lower outgassing occurred for the PAG 4 formulation despite its higher required exposure dose. Part of this difference may be due to the large difference in $\mathrm{pK}_{\mathrm{a}}$ between nonaflic acid and 1,3-benzenesulfonic acid.

Interestingly, the dinitrobenzyl derivatived PAG showed no outgassing of aromatic fragments in marked contrast to the behavior of the onium salt formulations.

This difference is most readily explained by the different mechanisms operative for photolysis with onium salts and nitrobenzyl esters (Scheme 1 and 3 respectively).
Table $1 \mathrm{Mw}$ and Boiling Points of Photoproducts

\begin{tabular}{|c|c|c|c|c|}
\hline $\begin{array}{l}\text { Entr } \\
y \\
\end{array}$ & Photoproduct & $\begin{array}{l}\text { Addi- } \\
\text { tive }^{\mathrm{a}}\end{array}$ & $\mathrm{Mw}$ & $\begin{array}{l}\mathrm{Bp} \\
{ }^{\circ} \mathrm{C} \\
\end{array}$ \\
\hline 1 & & $1,2,3$ & 134 & 169 \\
\hline 2 & $+(0)$ & 2,3 & 299 & $\begin{array}{l}>400 \\
\text { calc }^{\mathrm{b}}\end{array}$ \\
\hline 3 & & 1 & 260 & 258 \\
\hline 4 & & 1 & 392 & $\begin{array}{l}>400 \\
\text { calc }^{b}\end{array}$ \\
\hline 5 & & 2,3 & 431 & $\begin{array}{l}>400 \\
\text { calc }^{\mathrm{b}}\end{array}$ \\
\hline 6 & & 4 & 252 & $\begin{array}{l}>400 \\
\text { calc }^{\mathrm{b}}\end{array}$ \\
\hline 7 & & 4 & 490 & $\begin{array}{l}>400 \\
\text { calc }^{\mathrm{b}}\end{array}$ \\
\hline 8 & & $1+6$ & 958 & $\begin{array}{l}>400 \mathrm{c} \\
\text { calc }^{\mathrm{b}}\end{array}$ \\
\hline 9 & & $1+6$ & 538 & $\begin{array}{l}>400 \\
\text { calc }^{b}\end{array}$ \\
\hline
\end{tabular}

a) See Figure 1 for identity of photoadditives

b) For the origin of the experimental and calculated boiling points see reference [8]

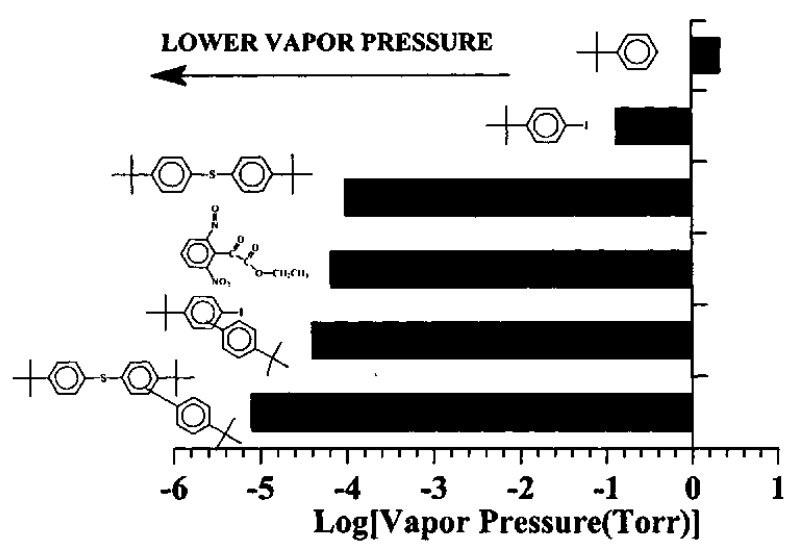

FIG. 3 Comparison of Vapor Pressures of Photoproducts at $25^{\circ} \mathrm{C}$ Derived from Representative PAG's.

Specifically, photolysis of the nitrobenzyl ester chomophore yields a nitroso compound of low volatility (Table 1 , entry 6) and a very large nonvolatile sulfonic acid (Table 1, entry 7).

The use of a nitrobenzyl ester PAG (4) in a $\mathrm{P}(\mathrm{NB} / \mathrm{MA} / \mathrm{TBA} / \mathrm{AA})$ resist formulations gives reasonable lithographic performance (for a nonoptimized system) albeit at a higher exposure dose (FIG. 4). 
Table 2. Summary of Results of High Activation Energy, $193 \mathrm{~nm}$ Resist and Low Activation Energy $248 \mathrm{~nm}$ Study.

\begin{tabular}{|l|l|l|l|l|}
\hline $\begin{array}{l}\text { Photo } \\
\text { additive }\end{array}$ & $\begin{array}{l}\text { Resin } \\
(\text { Exposure } \\
\text { Radiation })\end{array}$ & $\begin{array}{l}\text { Dose } \\
\mathrm{mJ} / \\
\mathrm{cm}^{2}\end{array}$ & $\begin{array}{l}\text { Rate } \\
\text { molecule/ } \\
\mathrm{cm}^{2} \text {-sec }\end{array}$ & $\begin{array}{l}\text { Rate } \\
\text { VS } \\
\text { PAG } \\
1\end{array}$ \\
\hline $\begin{array}{l}\text { PAG } \\
(1)\end{array}$ & $\begin{array}{l}\mathrm{NB}^{\mathrm{b}} \\
(193 \mathrm{~nm})\end{array}$ & 23 & $6.3 \times 10^{+11}$ & 1.00 \\
\hline $\begin{array}{l}\text { PAG } \\
(2)\end{array}$ & $\begin{array}{l}\mathrm{NB}^{\mathrm{b}} \\
(193 \mathrm{~nm})\end{array}$ & 11 & $1.4 \times 10^{+11}$ & 0.21 \\
\hline $\begin{array}{l}\text { PAG } \\
(3)\end{array}$ & $\begin{array}{l}\mathrm{NB}^{\mathrm{b}} \\
(193 \mathrm{~nm})\end{array}$ & 11 & $7.8 \times 10^{+10}$ & 0.12 \\
\hline $\begin{array}{l}\text { PAG } \\
(1)+ \\
(6)\end{array}$ & $\begin{array}{l}\mathrm{NB}^{\mathrm{b}} \\
(193 \mathrm{~nm})\end{array}$ & 36 & $4.6 \times 10^{+11}$ & 0.72 \\
\hline $\begin{array}{l}\text { PAG } \\
(4)\end{array}$ & $\begin{array}{l}\mathrm{NB}^{\mathrm{b}} \\
(193 \mathrm{~nm})\end{array}$ & 36 & $9.1 \times 10^{+10}$ & 0.14 \\
\hline $\begin{array}{l}\text { PAG } \\
(5)\end{array}$ & $\begin{array}{l}\text { PTVE }^{\mathrm{b}} \\
(248 \mathrm{~nm})\end{array}$ & 20 & $5 . \times 10^{+13}$ & 80 \\
\hline $\begin{array}{l}\text { PAG } \\
(7)+ \\
\text { ODA }\end{array}$ & $\begin{array}{l}\text { PTVE }^{\mathrm{b}} \\
(248 \mathrm{~nm})\end{array}$ & 20 & $2 \times 10^{+14}$ & 320 \\
\hline $\begin{array}{l}\text { PAG } \\
(7)\end{array}$ & $\begin{array}{l}\text { PTVE } \\
(248 \mathrm{~nm})\end{array}$ & $20^{\mathrm{c}}$ & $2 \times 10^{+14}$ & 320 \\
\hline $\begin{array}{l}\text { PAG } \\
(5)\end{array}$ & $\begin{array}{l}\text { "Bulky } \\
\text { Acetal" } \\
(248 \mathrm{~nm})\end{array}$ & $25^{\mathrm{d}}$ & $3 \times \times 10^{+13}$ & 50 \\
\hline
\end{tabular}

a) Average rate first 10 minutes of exposure.

b) $\mathrm{NB}=\mathrm{P}(\mathrm{NB} / \mathrm{MA} / \mathrm{TBA} / \mathrm{AA})$, See experimental section for further details on resin formulation.

c) Material with PTVE did not resolve because of high acid diffusion used dose with ODA additive for estimate.

d) Material did not clear used dose of maximum thickness loss as estimated clearing dose a sizing factor of 2.5 was used to estimate the resolution dose

The total outgassing as measured by GCMS from PAG's 2 and 3 (tris(t-butylphenyl)sulfonium PAG's) formulations was lower than that was observed in formulations containing the iodonium based PAG 1 (Table 3). In this case, the total isobutene outgassing did not differ significantly while the t-butylbenzene outgassing for PAG's 2 and 3 was lower by approximately an order of magnitude. The t-butyliodobenzene outgassing, not surprisingly, was totally suppressed. The arylsulfide photoproduct resulting from photolysis of PAG 2 or 3 was not observed probably because of its high boiling point (Table 1 , entry 2 ).

Moreover, it is possible that the sulfonium salts (2, $3)$ in the $P(N B / M A / T B A / A A)$ resist matrix proceed more through the singlet photolysis mechanism (Scheme 1) as inferred from the lower amount of t-butylbenzene observed as photoproduct compared to the formulation with PAG 1 (Table 3).

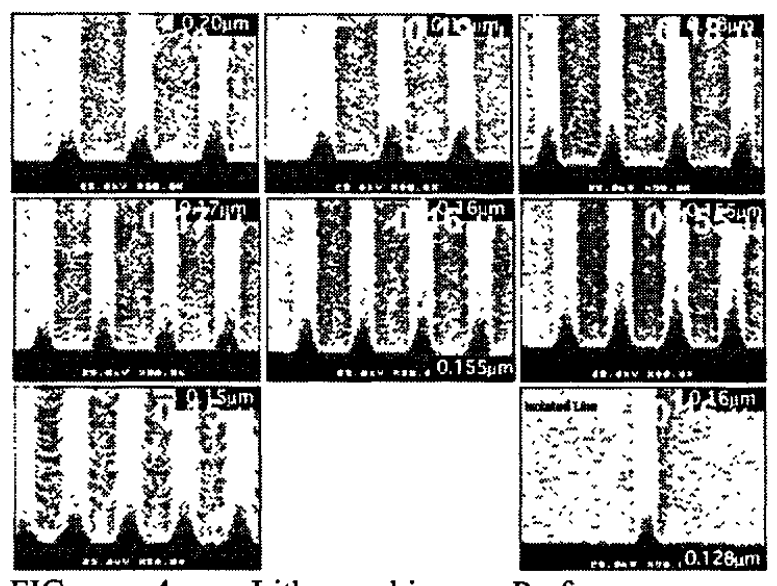

FIG. 4 Lithographic Performance of P(NB/MA/TBA/AA) Resist Formulation Containing Nitrobenzyl PAG (4) $\left(41 \mathrm{~mJ} / \mathrm{cm}^{2}\right.$, see experimental for processing)

Scheme 3.<smiles>CCOC(=O)C(OS(=O)(=O)c1cccc(S(=O)(=O)O[C@H](C(=O)OCC)c2c([N+](=O)[O-])cccc2[N+](=O)[O-])c1)c1c([N+](=O)[O-])cccc1[N+](=O)[O-]</smiles>

To summarize, from the standpoint of reducing the outgassing of volatile aromatic photoproduct, PAG 4 is ideal since total suppression aromatic compounds outgassing occurs. However, formulation with PAG 2 and 3 eliminated formation of the very harmful $t$ butyliodobenzene (Table 1, entry 3) while also significantly reducing formation of $t$ butylbenzene. 
Table 3. Comparison of Outgassing Products from Various Onium Salts (GCMS counts):

\begin{tabular}{|l|l|l|l|}
\hline $\begin{array}{l}\text { Photo } \\
\text { additive }\end{array}$ & PAG 1 & PAG 2 & PAG 3 \\
\hline $\begin{array}{l}\text { Iso- } \\
\text { butene }\end{array}$ & $3.20 \times 10^{5}$ & $2.30 \times 10^{5}$ & $1.40 \times 10^{5}$ \\
\hline $\begin{array}{l}\text { Perfluoro } \\
\text {-butane }\end{array}$ & $3.40 \times 10^{5}$ & 0 & 0 \\
\hline $\begin{array}{l}\text { t-Butyl- } \\
\text { benzene }\end{array}$ & $4.50 \times 10^{5}$ & $3.50 \times 10^{4}$ & $1.50 \times 10^{4}$ \\
\hline $\begin{array}{l}\text { Iodo-t- } \\
\text { butyl } \\
\text { benzene }\end{array}$ & $5.30 \times 10^{4}$ & 0 & 0 \\
\hline SUM & $1.16 \times 10^{6}$ & $2.65 \times 10^{5}$ & $1.55 \times 10^{5}$ \\
\hline $\begin{array}{l}\text { RATE } \\
\text { molecule } \\
\text { /cm }{ }^{2} \text {-sec }\end{array}$ & $6.3 \times 10^{11}$ & $1.4 \times 10^{11}$ & $7.8 \times 10^{10}$ \\
\hline
\end{tabular}

Table 4. Comparison of Outgassing Products Iodonium PAG with Nitrobenzyl PAG (GCMS counts):

\begin{tabular}{|l|l|l|}
\hline $\begin{array}{l}\text { Photo } \\
\text { additive }\end{array}$ & PAG 1 & PAG 4 \\
\hline Isobutene & $3.20 \times 10^{5}$ & $1.7 \times 10^{5}$ \\
\hline Perfluoro-butane & $3.40 \times 10^{5}$ & 0 \\
\hline t-Butyl-benzene & $4.50 \times 10^{5}$ & 0 \\
\hline Iodo-t-butyl benzene & $5.30 \times 10^{4}$ & 0 \\
\hline SUM & $1.16 \times 10^{6}$ & $1.7 \times 10^{5}$ \\
\hline $\begin{array}{l}\text { RATE } \\
\text { molecule } / \mathrm{cm}^{2} \text {-sec }\end{array}$ & $6.3 \times 10^{11}$ & $9.1 \times 10^{10}$ \\
\hline
\end{tabular}

Table 5. Comparison of Outgassing Products Iodonium PAG, the Effect of Radical Scavenger (GCMS counts):

\begin{tabular}{|l|l|l|}
\hline $\begin{array}{l}\text { Photo } \\
\text { additive }\end{array}$ & PAG I & $\begin{array}{l}\text { PAG 1 } \\
+6\end{array}$ \\
\hline Isobutene & $3.20 \times 10^{5}$ & $3.60 \times 10^{5}$ \\
\hline Unidentified fluorocarbon & 0 & $7.30 \times 10^{3}$ \\
\hline Perfluorobutane & $3.40 \times 10^{5}$ & $3.50 \times 10^{5}$ \\
\hline t-Butylbenzene & $4.50 \times 10^{5}$ & $1.18 \times 10^{5}$ \\
\hline Iodo-t-butyl benzene & $5.30 \times 10^{4}$ & 0 \\
\hline SUM & $1.16 \times 10^{6}$ & $8.52 \times 10^{5}$ \\
\hline $\begin{array}{l}\text { RATE } \\
\text { molecule/ } / \mathrm{cm}^{2} \text {-sec }\end{array}$ & $6.3 \times 10^{11}$ & $4.6 \times 10^{11}$ \\
\hline
\end{tabular}

\subsubsection{Effect of Anion Size, PAG 2 (Perfluorobutanesulfonate) vs PAG 3} (Perfluorooctanesulfonate):

The resist formulations with PAG's 2 and 3 were exposed to the same dose (Table 3). Increasing the perfluoroalkane chain length going from nonaflate PAG 2 to perfluorooctanesulfonate PAG 3 decreased isobutene and t-butylbenzene by a factor of 0.61 and 0.43 respectively (Table 3 ). The former could be explained by a reduction in room temperature diffusion of the larger acid and the latter due to the increased porosity of the polymer due to faster deprotection of isobutene and the concomitant room temperature diffusion of the outgassing PAG cationic fragments.

The use of a sulfonium salt PAG's in a $\mathrm{P}(\mathrm{NB} / \mathrm{MA} / \mathrm{TBA} / \mathrm{AA})$ resist formulations give comparable lithographic performance to that previously reported for PAG 1 .

\subsubsection{Effect of Radical Scavenger (6):}

The formulation containing PAG 1 alone was more lithographically sensitive (Table 2) than that containing a mixture of PAG 1 and the radical scavenger, methyl doxyl stearate (6). This lower sensitivity may be explained both by the small basicity of the nitroxide moiety and by a reduction of the quantum yield of photoacid by suppression of the triplet photoacid pathway. Comparing outgassing results (Table 5), it is seen that a dose increase of 1.6 times caused the emanations of isobutene to remain unchanged, that of t-butylbenzene to decrease by 3.8 times, and finally, that of 1-iodo-4-t-butyl benzene to decrease to zero (Table 5). This is indicative of a suppression of the triplet pathway for photogeneration of acid (Scheme 2) by reaction of radical cations and radicals with the doxyl radical 6. Specifically, the products resulting from the suppression of the triplet pathway are all expected to be non-volatile as is the iodobiphenyl moiety produced by the singlet path (Table 1, entry 4). Remaining, t-butyl benzene is probably a result of rapid reaction of t-butyl phenyl radical with the environment rather than by quenching with 6 .

Interestingly, a number of new fluorocarbon peaks showed up with the addition of 6 which did not correspond to the perfluoroalkanes seen in formulations containing either PAG 2 or 1 alone. These unknown materials may result from radical fragmentation reactions occurring either due to the higher dose employed or induced by reaction of perfluoroalkane fragments with 6 .

The addition of the doxyl additive to $\mathrm{P}(\mathrm{NB} / \mathrm{MA} / \mathrm{TBA} / \mathrm{AA})$ resist formulations gives reasonable lithographic performance (for a nonoptimized system) again at the cost of needing a higher exposure dose for resolution (FIG 5).

To summarize, the outgassing of the deleterious compound, 1-iodo-4-t-butyl benzene during exposure at $193 \mathrm{~nm}$ may be suppressed by either formulation with an iodonium salt PAG together with a radical scavenger such as 6 or by formulation with a sulfonium salt $(2,3)$. However, formulation with sulfonium salts better suppresses the formation of t-butylbenzene and the unknown 
fluorocarbon fragments, gives a far lower total amount of outgassing and does not cause loss of lithographic sensitivity.

\subsection{Scope of Experiments Done with Resin Protected with a Low Activation Energy Group.}

The low activation energy resist consisted of polyhydroxystyrene partially protected with a tbutylvinylether derived acetal group (PTVE) (Figure 6A). Also tested was a sample of a similar polyhydroxystyrene derived material protected with "bulky acetal" (Figure 6B) which has shown lower volume loss during exposure[9].
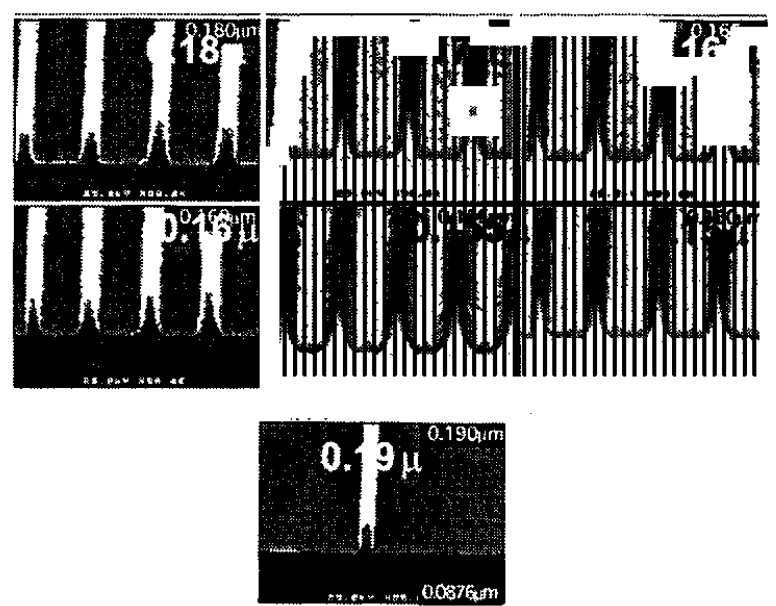

FIG. 5. Lithographic Performance of P(NB/MA/TBA/AA) Resist Formulation Containing Iodonium PAG (I) and the Radical Scavenger (6) (41 $\mathrm{mJ} / \mathrm{cm}^{2}$, see experimental for processing)

Although these materials are $248 \mathrm{~nm}$ resists, the observations seen for outgassing in these materials during irradiation at $248 \mathrm{~nm}$ should be applicable to similarly protected $193 \mathrm{~nm}$ resists. Previously, it has been shown that a photogenerator of cyclamic acid "sweet PAG" (PAG 5, Figure 1) could be used in a PTVE based low activation energy resist both as a PAG component capable of affecting cleavage of acetals grouping and as a photodecomposable base component[3g,h]. Moreover, it was shown that the sweet PAG formulations did not show any observable amount of film thickness loss immediately following exposure. This is because of the zwitterionic structure of the photoacid arising from the sweet PAG 5, cyclamic acid, which confers to it a very temperature dependent $\mathrm{pK}_{\mathrm{a}}$ which decreases with increasing temperature. This predicates that this photoacid only has sufficient acidity to effectively cleave the acetal moiety during the post-exposure bake and not during exposure.

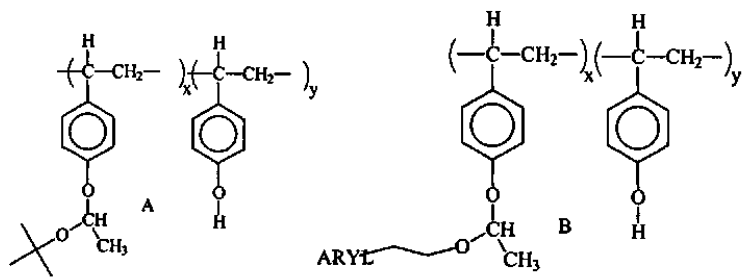

FIG. 6 Resin components of low activation energy $248 \mathrm{~nm}$ resist A) PTVE and B) Bulky Acetal

Such behavior is in contrast to the behavior of a PTVE formulation containing a conventional PAG such as bis(t-butylphenyl)iodonium 4methoxybenzenesulfonate, (7) and oxydianiline (ODA), base additive, which shows substantial film thickness loss during exposure. In this work, a comparison of the exact amount and nature of outgassing during exposure has been made between the PTVE formulation containing the sweet PAG alone and that containing the conventional PAG 7 and ODA. Also tested was a sample of the "bulky acetal" polymer matrix.

Table 6. Summary of Alkyl Outgassed Products from Low Activation Energy Resists.

\begin{tabular}{||c|c|c|c|c|c||}
\hline \hline $\begin{array}{l}\text { Resin } \\
\cdots\end{array}$ & $\begin{array}{c}\text { ADDI- } \\
\text { TIVE }\end{array}$ & \multicolumn{2}{|c|}{$\begin{array}{c}\text { Acetaldehyde } \\
\text { GCMS counts }\end{array}$} & \multicolumn{2}{|c|}{$\begin{array}{c}\text { Isobutene } \\
\text { GCMS } \\
\text { counts }\end{array}$} \\
\hline $\begin{array}{c}\text { Bulky } \\
\text { Acetal }\end{array}$ & PAG 5 & $3.1 \times 10^{+07}$ & 0.21 & $1.7 \times 10^{+04}$ & 0.053 \\
\hline PTVE & PAG 5 & $5.0 \times 10^{+07}$ & 0.33 & $6.0 \times 10^{+04}$ & 0.19 \\
\hline PTVE & $\begin{array}{c}\text { PAG 7 } \\
+ \\
\text { ODA }\end{array}$ & $1.6 \times 10^{+08}$ & 1.1 & $2.0 \times 10^{+05}$ & 0.63 \\
\hline PTVE & PAG 7 & $1.5 \times 10^{+08}$ & 1.0 & $3.2 \times 10^{+05}$ & 1.0 \\
\hline
\end{tabular}

Table 7. Summary of Aryl Outgassed Products from Low Activation Energy Resists.

\begin{tabular}{||l|l|l|l|l|l||}
\hline Resin & $\begin{array}{l}\text { ADDI } \\
\text { TIVE }\end{array}$ & \multicolumn{2}{|l|}{ t-butylbenzene } & \multicolumn{2}{|l|}{$\begin{array}{l}\text { t-butyliodo- } \\
\text { benzene } \\
\text { GCMS counts }\end{array}$} \\
\hline $\begin{array}{l}\text { Bulky } \\
\text { Acetal }\end{array}$ & $\begin{array}{l}\text { PAG } \\
5\end{array}$ & $1.1 \times 10^{+05}$ & 1.2 & $2.7 \times 10^{+04}$ & 0.77 \\
\hline PTVE & $\begin{array}{l}\text { PAG } \\
5\end{array}$ & $7.4 \times 10^{+04}$ & 0.82 & $2.4 \times 10^{+04}$ & 0.69 \\
\hline PTVE & $\begin{array}{l}\text { PAG } \\
7+ \\
\text { ODA }\end{array}$ & $4.3 \times 10^{+04}$ & 0.48 & $1.3 \times 10^{+04}$ & 0.37 \\
\hline PTVE & $\begin{array}{l}\text { PAG } \\
7\end{array}$ & $9.0 \times 10^{+04}$ & 1.0 & $3.5 \times 10^{+04}$ & 1.0 \\
\hline
\end{tabular}




\subsection{Results of Experiments Done with Resin Protected with a Low Activation Energy Group}

Table 1 summarizes the lithographic dose information along with the GC/MS results for the low activation energy resist formulations. Tables 6 and 7 breaks down the GC/MS results for the five 248-nm resists tested by exposure to $248 \mathrm{~nm}$ radiation, including the relative rates for each of the individual chemicals. FIG. 7 shows the normalized QCM results for the five DUV resists. The use of the sweet PAG (5) did substantially suppress the total amount of outgassing in the PTVE acetal resin compared to employing either the photogenerator of 4-methoxybenzenesulfonic acid (7) alone or in combination with ODA as measured by either the GCMS or QCM methods. The use of the "bulky acetal" appeared to further decrease the total amount of outgassing during exposure (Table 1, FIG. 7).

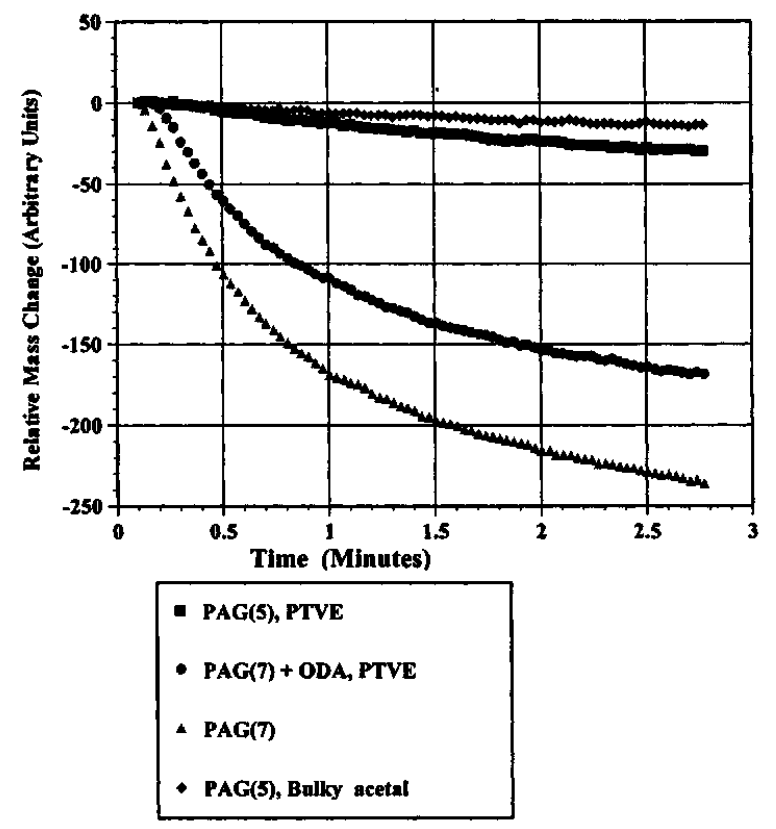

FIG 7. Normalized QCM results for DUV resists

In both formulations containing PAG 5 , the suppression of outgassing arose primarily from the reduction of products such as acetaldehyde resulting from photoacid induced cleavage of the acetal protecting group (Table 6). This concurs with the expected differences in acidity at room temperature between the zwitterionic cyclamic acid and conventional 4-methoxybenzenesulfonic acid photoproducts. This indicates that the strategy of suppressing the acid induced cleavage at room temperature worked. Unfortunately, the outgassing of deleterious aromatic products (Table 7) is not decreased by using PAG 5.
This is understandable given that the chromophore, bis(t-butylphenyl)iodonium, is the same for PAG's 5 and 7 . However, as discussed in the previous section the use of alternate chromophores or the addition of a radical scavenger such as 6 may be used to reduce the emission of aromatic moieties. Indeed examination of Table 6 indicates that there is a lowering of the evolved amount of t-butylbenzene and $t$-butyliodobenzene in the sample containing ODA which may be a result of ODA interfering with the triplet iodonium salt photolysis pathway either as a radical scavenger or by acting as a triplet quenching agent.

\section{CONCLUSION}

It has been shown that, for a high activation energy matrix, the use of sulfonium or nitrobenzyl PAG's instead of iodonium based PAG's can, respectively, substantially reduce or eliminate the amount of outgassing of deleterious aromatic compounds. The use of nitrobenzyl PAG is particularly interesting as it offers an easy route to the total suppression of deleterious aromatic outgassing. Although nitrobenzyl esters slightly degrade sensitivity, their use in lower activation energy resins may counteract this making them attractive for the total suppression of volatile aromatic photoproducts.

Similarly, the use of a radical scavenger additives such as the doxyl derivative, 6, can eliminate outgassing arising from $t$ butyliodobenzene and significantly suppress that of t-butylbenzene. The use of such additives should have general applicability to other onium salt (iodonium or sulfonium) formulated resist systems where volatile photoproducts arise from the triplet photochemical route and can be trapped by radical scavengers. Again the lowering of sensitivity they impart could be counteracted by using a lower activation energy resin.

FIG. 8 shows the imaging capability of a resist system containing a low volatility imaging system in an partially optimized high activation energy $\mathrm{P}(\mathrm{NB} / \mathrm{MA} / \mathrm{TBA} / \mathrm{AA})$ resin.

In low activation energy resist systems, the use of a zwitterionic PAG such as 5 can largely decrease outgassing originating from premature deprotection of low activation energy groups. The use of PAG 5, does not, however, suppress formation of aromatic fragments originating from the bis(t-butylphenyl)iodonium chromophore. The employment of alternate chromophores and/or the addition of radical scavengers may reduce the outgassing of aromatic moieties. 


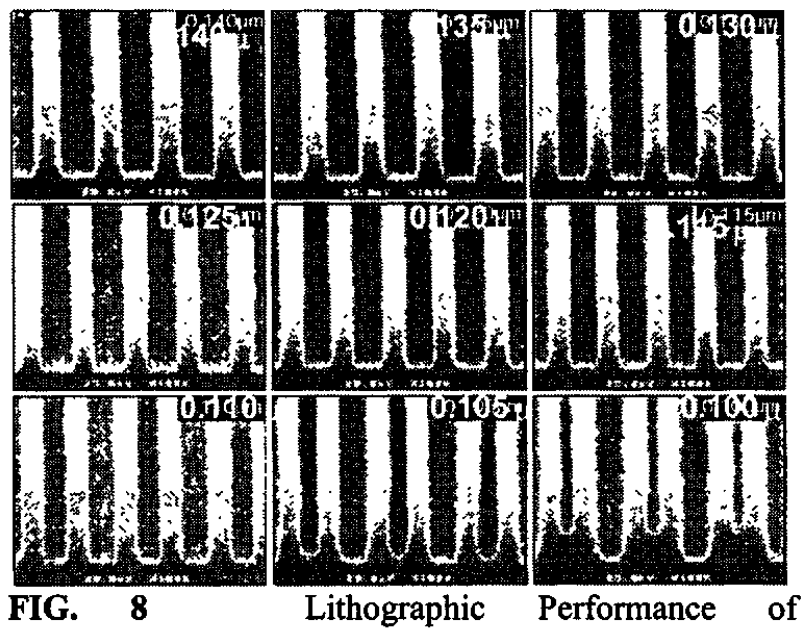

P(NB/MA/TBA/AA) Resist Formulation Containing Low Volatility PAG Imaging System in an partially optimized resin imaged using a alternating phase shift mask (15 mJ/ $\mathrm{cm}^{2}$, see experimental for processing)

\subsection{Synthesis}

\section{EXPERIMENTAL}

The synthesis of PNB/MA/TBA /AA)[3a,d], oligomeric cholate based dissolution inhibitors[3b,c], monomeric cholate dissolution inhibitor[3], and bis(4-t-butylphenyl)iodonium 4methoxybenzenesulfonate (PAG 7) [10] were done as previously described. The Synthesis of 2,6dinitrobenzylethoxycarbonyl) benzyl 1,3benzenesulfonate (PAG 4), was made in a manner as described before[5]. The synthesis of PAG 1 and 5 was carried as previously described[3h]. The synthesis of PTVE was done according to the procedure described by the literature[11]. The synthesis of PAG 2 and 3 was done by first making tris(t-butylphenyl)sulfonium chloride and then doing an interfacial exchange with an excess of either potassium perfluorobutanesulfonate or potassium perfluorooctanesulfonate respectively (from Aldrich and Fluka). A sample of low volume loss acetal resin was obtained from Arch Chemicals. Methyl 5-doxyl stearate was obtained from the Aldrich Chemical Company.

\subsection{Lithography}

Formulation of resist based on $\mathrm{P}(\mathrm{NB} / \mathrm{MA} / \mathrm{TBA} / \mathrm{AA})$ containing PAG 1 was done as before[3h]. Formulation of resists containing PAG 2 and 3 was done so as to maintain the same molar quantity as was employed for the PAG 1 formulation. The methyl 5-doxyl stearate resist solution contained a wt ratio of PAG 1 to methyl 5-doxyl stearate of 1.2 .

Processing of $193 \mathrm{~nm}$ resists formulated with P(NB/MA/TBA/AA): The wafers were coated with resist on a MTI track and baked at $140^{\circ} \mathrm{C}$ for 90 seconds. The spin speed was $3000-3900 \mathrm{rpm}$ to get a nominal resist thicknesses of 0.40-0.36 $\mu \mathrm{m}$. The resist thickness was measured by a Nanospec AFT thickness gauge using a refractive index of 1.51. For lithographic images a post-exposure bake was done at $155^{\circ} \mathrm{C}$ for 90 seconds followed by a development consisting of an $8 \mathrm{~s}$ dispense and a $24 \mathrm{~s}$ puddle using Arch Chemicals ODP 462 followed by a $30 \mathrm{~s}$ distilled water rinse.

SEM cross-section were obtained on a JEOL 6400 F SEM or a Hitachi 4200 SEM.

Formulation of resist based on PTVE. containing $2.5 \mathrm{wt} \%$ PAG 5 or PAG 7 was done as before ${ }^{3 \mathrm{~h}}$. For the PAG 7 formulations containing ODA a and 1/15 ratio PAG/BASE wt ratio was employed. Formulation of the resist containing the low volume loss acetal matrix were prepared in a similar fashion using $2.5 \mathrm{wt} \%$ PAG 5.

Processing for PTVE and low volume acetal matrix based resists: The wafers were coated with resist on a MTI track and baked at $130^{\circ} \mathrm{C}$ for 90 seconds. The spin speed was $3000-3900 \mathrm{rpm}$ to get a nominal resist thicknesses of $0.71-0.76 \mu \mathrm{m}$. The resist thickness was measured by a Nanospec AFT thickness gauge using a refractive index of 1.56 for resists based on protected poly(hydroxystyrene).

\subsection{GCMS/QCM}

The exposures at 193 and $248 \mathrm{~nm}$ for the P(NB/MA/TBA/AA) and PTVE resins respectively and the subsequent measurements of outgassing by GC/MS and QCM were done as outlined by MIT Lincoln Laboratory[1]. For materials which show a low levels of outgassing, differences in rate observed by QCM are less dependable than those observed by GC/MS. This is because of the small amount of material measured coupled with the differences in sensitivities between the two techniques and the imprecision's of extrapolating into a shorter time frame for QCM measurements. In GC/MS the transfer tube is only heated to $160^{\circ} \mathrm{C}$ and could conceivably not detect volatiles of intermediate volatility. Conversely, because of the mass cutoff employed in the MS detector small volatiles such as $\mathrm{CO}_{2}$ are not detected.

\section{ACKNOWLEDGMENTS}

We wish to thank Roxanne Williams of Arch Chemicals for the SEM work. We also wish to thank Jim Sweeney of Lucent for the lithographic processing. The Lincoln Laboratory portion of this 
and Development Agreement between Lincoln Laboratory and Lucent Technologies. "Opinions, interpretations, conclusions, and recommendations are those of the authors and are not necessarily endorsed by the United States Air Force.

\section{REFERENCES}

1. R.R. Kunz, D.K. Downs, "Photoresist Outgassing at 193 nm," Proc Fourth International Symposium on $193 \mathrm{~nm}$ Lithography, Tyrol Austria, 14-17 September 1998. A detailed written summary of this work will appear in the J. Vac. Sci. Technol. 17(6) (1999)

2. For some leading references on $193 \mathrm{~nm}$ resists, see: (a) R.D. Allen; I. Y. Wan; G. M. Wallraff; R. A. DiPietro; D. C. Hofer; R. R. Kunz J. Photopolym. Sci. Technol. 8, (1995) 623; (b) R.D. Allen; I. Y. Wan; G. M. Wallraff; R. A. DiPietro; D. C. Hofer; R. R. Kunz in Microelectronics Technology, Polymers for Advanced Imaging and Packaging, E. Reichmanis; C. K. Ober; S. A. MacDonald.; T. Iwayanagi; T. Nishikubo, Eds.; ACS Symposium Series 614, American Chemical Society: Washington, DC, (1995); p 255-270; (c) K. Nakano; K. Maeda; S. Iwasa; T. Ohfuji; E. Hasegawa Proc. SPIE, 2438 (1995) 433-440;. (d) N. Nozaki; Y. Kaimoto; M. Takahashi; S. Takeshi; N. Abe Chem. Mater. 6, (1994) 1492-1498; (e) R.R. Kunz; S.C. Palmateer; A.R. Forte; R.D. Allen; G.M. Wallraff; R.A. DiPietro; D.C. Hofer Proc. SPIE, 2724 (1996). 365.

3. (a) T.I. Wallow; F. M. Houlihan; O. Nalamasu; E.A. Chandross; T.X. Neenan; E. Reichmanis Proc. SPIE, 2724 (1996) 355; (b) F. M. Houlihan; T. I. Wallow; A. Timko; E. Neria; R. Hutton; R. Cirelli; O. Nalamasu; E. Reichmanis Proc. SPIE, 3049 (1997) 84, (c) F. M. Houlihan; T. I. Wallow; A. Timko; E. Neria; R. Hutton; R. Cirelli; O. Nalamasu; E. Reichmanis. J. Photopolym. Sci. Technol., 10, (1997) 511; (d) F.M. Houlihan; T.I. Wallow; O. Nalamasu; E. Reichmansis. Macromolecules, 30 (1997) 6517. (f) $\mathrm{O}$. Nalamasu, T. I. Wallow, F. M. Houlihan, E. Reichmanis, A. G. Timko, G. Dabbaugh, R. A. Cirelli, R. S. Hutton, and A. E. Novembre, "Recent Progress in Resist Materials for 193 nm Lithography," Future Fab International, Issue 2, Vol 1, (1997) 159. (g) F.M. Houlihan, J.M. Kometani, A.G. Timko, R.S. Timko, RA. Cirelli, E. Reichmanis, O. Nalamasu, A. H. Gabor, A. N. Medina, J. J. Biafore, S. G. Slater
J. Photopolym. Sci. Technol., 11, (1998) 419; (h) F.M. Houlihan, J.M. Kometani, A.G. Timko, R.S. Timko, RA. Cirelli, E. Reichmanis, O. Nalamasu, A. H. Gabor, A. N. Medina, J. J. Biafore, S. G. Slater Proc SPIE, 3333, (1998) 73.

4. J.V. Crivello, J.L. Lee, J. Polym. Sci. Part A, Polym. Chem., 27, 1989, 3951.

5. (a) F.M. Houlihan, E. Chin, O. Nalamasu, J.M. Kometani, T.X. Neenan, A. Pangborn, Proc. SPIE, 2195, 137, 1994, (b) F. M. Houlihan, E. Chin, O. Nalamasu United States Patent $5,830,619$ Nov 3, (1998).

6. (a) J.L. Dektar, N. P. Hacker, J. Org. Chem., 53, (1988) 1833; (b) J.L. Dektar, N. P. Hacker, J. Am. Chem. Soc., 112, (1990) 6004; (c) N. Ohmori, Y. Nakozono, M. Hata, T. Hoshino, M. Tsuda, J. Phys. Chem. 102(6), (1998), 927 and references therein.

7. For a discussion of the structural parameters leading to thermal stability of nitroxyl radicals see "Methoden Der Organishen Chemie Organische/(Houben-Weyl)," Editors H.K. Buchel, J. Falbe, H. Hagemann, R. Kreher, H. Kropf, M. Regitz, E. Schaumann, H.G. Padeken; Georg Thieme Verlag New York (1990) "Nitroxyl-Radikale, Nitroxide," K. Doser p395.

8. All experimental boiling points taken from: "CRC Handbook 56 $6^{\text {th }}$ edition", Editor Robert C. Weast CRC Press, Cleveland Ohio 1974. In certain cases the boiling point was normalized to 1 atmosphere by using the procedure described in the CRC Handbook $56^{\text {th }}$ Edition Editor R. C. Weast (1975-76) D177. Calculated boiling points were estimated knowing the boiling points of the compounds found in the CRC Handbook as follows: Entries 2, 4, 5 were estimated knowing benzene $\left(80^{\circ} \mathrm{C}\right)$, t-butyl benzene $\left(169^{\circ} \mathrm{C}\right) 1,4$-dit-butylbenzene $\left(236^{\circ} \mathrm{C}\right) \quad 1,3,5-\quad$ tri-t-butyl benzene $\left(255^{\circ} \mathrm{C}\right)$ phenylsulfide $\left(296^{\circ} \mathrm{C}\right)$ and 4 iodobiphenyl $\left(320^{\circ} \mathrm{C}\right.$ decomposition); Entries 6 and 7 were estimated knowing $\left(80^{\circ} \mathrm{C}\right)$, ethyl benzoylformate $\left(249^{\circ} \mathrm{C}\right)$, nitrobenzene $\left(210^{\circ} \mathrm{C}\right)$ nitrosobenzene $\left(164^{\circ} \mathrm{C}\right)$, dinitrobenzene $\left(300^{\circ} \mathrm{C}\right)$ and that 4 -bromosulfonic acid has a boiling point of $252^{\circ} \mathrm{C}$ and that the ballast present on the aryl sulfonate in this instance is much larger Entry 8 is a salt; Entry 9 was estimated knowing 1-amino-3cyclohexyloxypropane $\left(227^{\circ} \mathrm{C}\right)$, butylbenzene $\left(80^{\circ} \mathrm{C}\right)$, cyclopentylbenzene $\left(219^{\circ} \mathrm{C}\right)$ and $\mathrm{t}-$ butyl benzene $\left(169^{\circ} \mathrm{C}\right)$ 
9. S. Malik, A.J. Blakeney, L. Ferreira, J. Sizensky, B.M. Maxwell, T. Kocab, T.R. Sarubbi, B.A. Blachowic, M.J. Bowden, J. Photopolym. Sci. Technol., 11 (1998) 431.

10. F. M. Houlihan, O. Nalamasu, E. Reichmanis, A.G. Timko, U. Varlemann, T. I. Wallow, N. Bantu, J. Biafore, T. Sarubbi, P. Falcigno, H-J. Kirner, N. Munzel, K. Petschel, H-T. Schacht and R. Schultz, SPIE Proc. 3049,
(1997) 466.

11. C. Mertesdorf, N. Münzel, H. Holzwarth, P. Falcigno, H.-T Schacht., O. Rohde, R. Schulz, S. G. Slater D. Frey, O. Nalamasu, A. Timko, T. X. Neenan SPIE Proceedings Vol. 2438 (1995) 84 b) H.-T Schacht, N. Münzel, P. Falcigno, H. Holzwarth, J. Schneider $J$. Photopolymer Sci. Tech., 9(4) (1996) 573. 